\title{
Short term effect of oxygen on renal haemodynamics in patients with hypoxaemic chronic obstructive airways disease
}

\author{
S V Baudouin, J Bott, A Ward, C Deane, J Moxham
}

\begin{abstract}
Background Oxygen therapy is effective in the prevention and treatment of oedematous exacerbations of cor pulmonale. As renal blood flow is reduced in cor pulmonale a study was designed to investigate whether one of the beneficial effects of oxygen was to increase renal blood flow. The effect of oxygen therapy on renal haemodynamics measured noninvasively was examined in patients with chronic obstructive airways disease and previous episodes of oedema.

Methods Renal blood flow waveforms were recorded in a single vessel by colour flow Doppler ultrasound in nine hypoxaemic patients $\left(\mathrm{PaO}_{2}\right)$ (arterial oxygen tension $<8 \mathrm{kPa}$ while they were breathing air) with chronic obstructive airways disease and previous oedema and eight age matched normoxaemic volunteers (arterial oxygen saturation $\left(\mathrm{SaO}_{2}\right) \mathbf{9 7 \%}$ or more when breathing air) while they were breathing air and oxygen. $\mathrm{SaO}_{2}$ and transcutaneous $\mathrm{PaO}_{2} \quad\left(\mathrm{TcPO}_{2}\right)$ and $\mathrm{PaCO}_{2}$ $\left(\mathrm{TcPCO}_{2}\right)$ were monitored. Five renal velocity profile recordings were made from the same segmental vessel with the patient breathing room air for one hour followed by oxygen titrated to achieve an oxygen saturation of $95 \%$ or more without a rise in $\mathbf{T c P C O}_{2}$ for 15 minutes. Control subjects breathed $35 \%$ oxygen.
\end{abstract}

Results Nosignificant change in the pulsatility index (a measure of distal vascular resistance) or mean height of the waveform (Tamx, a measure of renal blood flow) occurred in the control subjects while they were breathing air or oxygen. The pulsatility index of the patients with chronic obstructive airways disease was significantly greater than that in the control subjects breathing air (1.44 (SD 0.28) $v 1.03(0.14)$. Breathing oxygen was associated with an increase in $\mathrm{TcPO}_{2}$ in the patients (from $6.9(1.9)$ to $11.5(0.7)$ $\mathrm{kPa}$ ), a fall in pulsatility index (from 1.44 $(0.28)$ to $1.26(0.14)$ and an increase in Tamx (from 0.187 (0.055) to 0.234 (0.087) $\mathbf{m} / \mathbf{s})$.

Conclusions The results suggest that renal vascular resistance is increased in patients with chronic obstructive airways disease and hypoxaemia and that short term oxygen therapy reduces renal vascular resistance and increases blood flow. Some of the benefits of oxygen therapy in cor pulmonale may be due to improvements in renal haemodynamics.

The pathogenesis of oedema in chronic respiratory failure, "cor pulmonale," is controversial. ${ }^{12}$ Right ventricular failure due to secondary pulmonary hypertension has been largely disproved ${ }^{3}$ and the increased levels of salt and water retaining hormones reported ${ }^{4}$ could be explained by volume depletion due to diuretic treatment. ${ }^{5}$

Reduced renal blood flow has been consistently reported in patients with respiratory failure from chronic obstructive airways disease, ${ }^{6-11}$ with a further fall occurring during episodes of oedema. ${ }^{1213}$ The glomerular filtration rate is relatively well maintained in cor pulmonale, ${ }^{6-911}$ suggesting that compensatory efferent glomerular vasoconstriction occurs. The resulting fall in peritubular capillary blood pressure and rise in colloid osmotic pressure could then explain the excessive salt and water retention found in cor pulmonale. ${ }^{14}$

The cause of the reduction in renal blood flow is unknown. Oxygen therapy reduces the number of exacerbations of oedema in patients with chronic obstructive airways disease $\mathrm{e}^{15}$ and causes resolution of the oedema, ${ }^{4}$ suggesting that chronic hypoxia could alter renal blood flow. Reports that oxygen therapy failed to improve renal flow in hypoxaemic patients with chronic obstructive airways disease, ${ }^{911} 16^{17}$ however, discredited the idea that alterations in renal haemodynamics could be important in causing fluid retention.

Previous studies of renal haemodynamics in chronic obstructive airways disease may have failed to detect oxygen induced changes in renal flow because of failure to control for the effect of hypercapnia, technical problems with the clearance methods used to record renal blood flow, the use of hypoxic challenges during the studies, and the invasive nature of the haemodynamic recordings.

Colour flow Doppler ultrasound is a noninvasive technique for assessing changes in renal haemodynamics and has been used to document changes in renal flow in transplanted kidneys ${ }^{18}$ and after dopamine infusions in critically ill patients. ${ }^{19}$ We have used this technique to record changes in renal haemodynamics in patients with hypoxaemic chronic obstructive airways disease breathing air and controlled oxygen and to compare these with renal haemodynamics in normoxaemic control subjects. 


\section{Methods}

PATIENTS AND CONTROLS

We studied nine patients with chronic respiratory failure $\left(\mathrm{PaO}_{2}<8 \mathrm{kPa}\right.$ with room air) due to chronic bronchitis and emphysema $\left(\mathrm{FEV}_{1}<1.51, \mathrm{FEV}_{1} / \mathrm{FVC}\right.$ ratio $\left.<70 \%\right)$. All patients had been previously oedematous but were clinically stable at the time of the study with no recent change in medication. They had no evidence of cardiac, liver, or renal disease (normal results of electrocardiography and serum biochemistry). All patients gave informed consent for the study, which was approved by the hospital ethics committee. Eight age matched normoxaemic subjects (arterial oxygen saturation $\left(\mathrm{SaO}_{2}\right)$ with air $\geqslant 97 \%$ recorded by pulse oximetry) acted as controls.

\section{METHODS}

A pilot study was performed initially to determine the time course of changes in renal haemodynamics and the within patient coefficient of variation of the technique. Repeated recordings of renal haemodynamics were made at 15 minute intervals for one hour in three hypoxaemic patients with chronic obstructive airways disease breathing $35 \%$ oxygen. On the basis of the initial study a period of 15 minutes of oxygen therapy was chosen to minimise rises in arterial carbon dioxide tension $\left(\mathrm{PCO}_{2}\right)$.

All studies were performed in the afternoon. On arrival patients were seated in a semi-erect position breathing room air. Transcutaneous $\mathrm{PO}_{2}\left(\mathrm{TcPO}_{2}\right)$ and $\mathrm{PCO}_{2}(\mathrm{TcPCO})$ were recorded (Radiometer TCM 3) after dry gas calibration and stabilisation at $45^{\circ} \mathrm{C}$ followed by calibration with an arterialised ear lobe capillary blood sample. ${ }^{20}$ Oxygen saturation was recorded by finger pulse oximetry (Ohmeda Biox II). After one hour renal haemodynamics were recorded (see below), with simultaneous measurements of $\mathrm{SaO}_{2}, \mathrm{TcPO}_{2}$ and $\mathrm{TcPCO}_{2}$. Patients then received oxygen by a controlled oxygen mask (Ventimask), starting with $24 \%$. The inspired oxygen concentration $\left(\mathrm{FIO}_{2}\right)$ was then titrated against oxygen saturation until a saturation of $95 \%$ or greater was achieved without a rise in $\mathrm{TcPCO}_{2}$. The patient then continued at the same $\mathrm{FIO}_{2}$ for a further 15 minutes, after which renal artery velocity profiles, oxygen saturation, $\mathrm{TcPO}_{2}$, and $\mathrm{TcPCO}_{2}$ were recorded.

Renal haemodynamics were also measured in eight normal subjects breathing room air, air by face mask (as placebo oxygen), and 35\% oxygen.

\section{RENAL HAEMODYNAMIC MEASUREMENTS}

Colour flow Doppler ultrasound examination of renal haemodynamics was carried out with an Acuson 128 scanner with pulsed and colour Doppler scanning facilities. A $3.5 \mathrm{MHz}$ probe (all modes) was used. The sample volume size of the spectral Doppler was 3-4 $\mathrm{mm}$ and the wall filter setting $50 \mathrm{~Hz}$. Either the left or the right kidney was used, depending on accessibility. Kidneys were scanned in the longitudinal plane.

Flow velocities were measured in a vessel at segmental-interlobar level, chosen from the colour map of the renal vasculature. This level of artery was chosen, firstly, because colour images of segmental-interlobar vessels were obtained consistently in all patients and, secondly, because at this level and size of vessel the flow profile within the vessel is more fully developed than in the renal artery. ${ }^{21}$

The colour image of the vessel enabled beam-vessel angle corrections to be made to the pulsed wave Doppler measurements, thereby permitting velocity measurements to be made from the received Doppler frequency shift. In practice, the angle was kept within $20^{\circ}$ to keep errors to a minimum. Five sets of measurements were obtained at each stage of the study. As flow velocity changes with the depth of the vessel, only vessels at about the same depth ( 30 $\mathrm{mm}$ from the renal capsule) were selected in different subjects.

Measurements were made of maximum systolic velocity, minimum diastolic velocity, and time averaged maximum velocity (Tamx) in the cardiac cycle. No attempt was made to measure the cross sectional area of the vessel under investigation. The pulsatility index (PI) ${ }^{22}$ was calculated as:

Maximum height of waveform - minimum height of waveform mean height of waveform

\section{STATISTICAL ANALYSIS}

Values for the pulsatility index and Tamx in control subjects breathing air, air by mask, and oxygen were compared by two way analysis of variance. Comparison between flow velocities for controls and patients was made by the unpaired $t$ test and between air and oxygen for patients by paired $t$ test. Results are presented as means with standard deviations in parentheses unless otherwise indicated.

\section{Results}

DESCRIPTIVE DATA (TABLE 1)

The mean ages of the patients and controls were similar ( 62 and 58 years). All patients had severe airways obstruction (mean $\mathrm{FEV}_{1} 0.65 \mathrm{l}$, $\mathrm{FEV}_{1} /$ vital capacity $35 \%$ ) and were hypoxaemic when breathing air (mean $\mathrm{PaO}_{2} 6.9 \mathrm{kPa}$ ). Three patients were hypercapnic at the time of the study $\left(\mathrm{PaCO}_{2}>6.0 \mathrm{kPa}\right)$. All patients had been oedematous and three were oedematous at the time of the study. Medication included inhaled salbutamol (9 patients), inhaled

Table 1 Descriptive data, spirometric values, arterial blood gas and oxygen saturation (for air) for control subjects and patients with chronic obstructive airways disease (mean values with SD or range)

\begin{tabular}{|c|c|c|c|c|}
\hline & Contr & & Patien & \\
\hline Number & 8 & & 9 & \\
\hline Male/female & $4 / 4$ & & $9 / 0$ & \\
\hline Age (y) & & $(55-61)$ & 62 & $(54-72)$ \\
\hline $\mathrm{FEV}_{1}$ (1) & $2 \cdot 58$ & $(0.73)$ & 0.65 & $(0 \cdot 37)$ \\
\hline FVC (1) & 3.44 & $(0 \cdot 76)$ & 1.85 & $(0.65)$ \\
\hline $\mathrm{PaO}_{2}(\mathrm{kPa})$ & - & & 6.9 & $(4 \cdot 4-8 \cdot 1)$ \\
\hline $\mathrm{PaCO}_{2}(\mathrm{kPa})$ & - & & $6 \cdot 4$ & $(4 \cdot 9-9 \cdot 1)$ \\
\hline $\begin{array}{l}\text { pH } \\
\text { Oxygen }\end{array}$ & - & & $7 \cdot 43$ & $(0.05)$ \\
\hline saturation (\%) & 97 & $(97-98)$ & 84 & $(64-93)$ \\
\hline
\end{tabular}

FEV - forced expiratory volume in one second; FVC forced vital capacity; $\mathrm{PaO}_{2}$-arterial oxygen tension; $\mathrm{PaCO}_{2}$-arterial carbon dioxide tension. 
Table 2 Mean height of the waveform (Tamx) and pulsatility index (PI) (for air and oxygen) for the nine patients with chronic obstructive airways disease

\begin{tabular}{|c|c|c|c|c|}
\hline \multirow{2}{*}{$\begin{array}{l}\text { Patient } \\
\text { No }\end{array}$} & \multicolumn{2}{|c|}{$\operatorname{Tamx}(\mathrm{m} / \mathrm{s})$} & \multicolumn{2}{|l|}{$P I$} \\
\hline & Air & $\mathrm{O}_{2}$ & Air & $\mathrm{O}_{2}$ \\
\hline 1 & $0 \cdot 195$ & $0 \cdot 236$ & 1.21 & $1 \cdot 19$ \\
\hline 2 & $0 \cdot 204$ & $0 \cdot 276$ & $1 \cdot 88$ & $1 \cdot 35$ \\
\hline 3 & 0.312 & 0.432 & $1 \cdot 32$ & $1 \cdot 30$ \\
\hline 4 & $0 \cdot 169$ & $0 \cdot 200$ & 1.49 & 1.41 \\
\hline 5 & $0 \cdot 109$ & $0 \cdot 111$ & 1.90 & $1 \cdot 35$ \\
\hline 6 & $0 \cdot 194$ & $0 \cdot 244$ & $1 \cdot 26$ & $1 \cdot 22$ \\
\hline 7 & $0 \cdot 184$ & $0 \cdot 190$ & $1 \cdot 29$ & $1 \cdot 31$ \\
\hline 8 & $0 \cdot 147$ & $0 \cdot 205$ & 1.46 & $1 \cdot 28$ \\
\hline 9 & $0 \cdot 172$ & $0 \cdot 213$ & $1 \cdot 14$ & 0.92 \\
\hline Mean & $0 \cdot 187$ & $0 \cdot 234^{\star}$ & 1.44 & $1 \cdot 26 \dagger$ \\
\hline
\end{tabular}

${ }^{\star} \mathrm{p}<0.01 ; \mathrm{\dagger p}<0.05$.

ipratropium bromide (6), prednisolone (4), theophylline (7), diuretics (8), and an inhaled corticosteroid (2).

\section{RENAL HAEMODYNAMICS}

The pilot study showed that the renal vascular response to oxygen was rapid and sustained With $35 \%$ oxygen the pulsatility index had fallen by $15 \%(2 \%)$ at 5 minutes, $14 \%(2 \%)$ at 15 minutes, $16 \%(2 \%)$ at 30 minutes, and $19 \%$ $(2 \%)$ at 60 minutes. The mean within patient coefficient of variation was $6 \%$ for Tamx and $5 \%$ for the pulsatility index.

There was no significant difference in the mean (SD) pulsatility index for the control subjects between air $(1.03(0.14))$, air by mask $(1.05(0.16))$, and oxygen $(1.03(0.13))$. Tamx $(\mathrm{m} / \mathrm{s})$ also did not differ significantly between air $(0.228(0.050))$, air by mask $(0.209(0.043))$, and oxygen $(0.211(0.047))$. With air the pulsatility index for control subjects $(1.03)$ was significantly less $(p=0.008)$ than that for patients with chronic obstructive airways disease $(1.44(0 \cdot 28))$.

$\mathrm{TcPo}_{2}$ improved in patients with chronic obstructive airways disease when they were breathing oxygen from a mean of $6.9(1.9)$ to $11.5(0 \cdot 7) \mathrm{kPa}$. Carbon dioxide tensions did not rise significantly $(6.4(1.6)$ while they were breathing air and $6.7(1.5) \mathrm{kPa}$ with oxygen) With oxygen the pulsatility index fell by $13 \%$ $(1.44(0.28)$ to $1.26(0.14)$; $p<0.05$ : table 2$)$ and Tamx increased by $25 \%(0.187(0.055)$ to $0.234(0.087) \mathrm{m} / \mathrm{s} ; \mathrm{p}<0.01$ : table 2$)$.

\section{Discussion}

The non-invasive technique of colour flow Doppler ultrasound used to measure renovascular resistance suggests that resistance is increased in hypoxaemic patients with chronic obstructive airways disease and previous episodes of cor pulmonale and is reduced with oxygen therapy. Absolute renal blood flow or resistance cannot be measured with this technique but the pulsatility index is known to increase with increased vascular resistance. ${ }^{1822-25}$ The pulsatility index decreased significantly, by $13 \%$, with oxygen therapy in the hypoxaemic patients, and the time averaged maximum velocity in the artery under inves- tigation increased simultaneously by $25 \%$. This indicates an increase in absolute flow unless vascular diameter decreased, which is unlikely in view of the fall in the pulsatility index.

Studies on normal subjects have generally shown an increase in renal blood flow with moderate acute hypoxaemia, ${ }^{26}$ probably because of increased catecholamine concentrations and cardiac output. ${ }^{27}$ Paradoxically, renal blood flow is low in hypoxaemic patients with chronic obstructive airways disease despite normal or even increased cardiac output. During oedematous exacerbations flow is further reduced but it recovers to pre-exacerbation levels after the resolution of fluid overload..$^{6-13}$

There is evidence to suggest a causal relationship between arterial oxygenation and the improvement in renal haemodynamics. Patients having long term oxygen therapy have fewer oedematous exacerbations ${ }^{15}$ and oedema may resolve, and renal flow improve, with oxygen therapy. ${ }^{4}$ Most studies, however, of renal blood flow with oxygen therapy have found either no change or a fall in flow. ${ }^{911} 161728$

Fishman et $a l^{9}$ studied changes in renal blood flow in hypoxaemic patients with chronic obstructive airways disease at different inspired oxygen concentrations including an $\mathrm{FrO}_{2}$ of $16 \%$. Effective renal plasma flow was measured by the $p$-aminohippurate method with direct renal vein cannulation. Renal plasma flow increased during hypoxaemia and decreased during oxygen therapy ( $30 \%$ oxygen). Davies et al $^{11}$ also reported a fall in renal plasma flow in three hypoxaemic patients with chronic obstructive airways disease having oxygen therapy, using the aminohippurate method. Studies of the effect of oxygen therapy on renal blood flow, measured by radioisotope techniques, have produced conflicting results. ${ }^{161728}$ Kilburn et al measured renal flow by aminohippurate clearance in 27 patients with chronic obstructive airways disease breathing hypoxic gas mixtures. Renal flow and sodium excretion were reduced when $\mathrm{PaO}_{2}$ fell below $5.3 \mathrm{kPa}$. Others, ${ }^{16}{ }^{17}$ however, have found no significant change in renal flow with oxygen.

Important differences in study design may account for the past failure to observe a relationship between $\mathrm{PaO}_{2}$ and renal flow. The most important of these is the degree of carbon dioxide retention that patients have developed during oxygen therapy. ${ }^{11} 16$ Hypercapnia reduces renal flow through catecholamine release and by a neurally mediated action, ${ }^{29}$ and in patients with hypoxaemic chronic obstructive airways disease there is also indirect evidence that hypercapnia decreases renal flow. ${ }^{230}$ The confounding problem of hypercapnia is illustrated by the recent study of Mannix et al, ${ }^{17}$ who measured renal blood flow by ${ }^{131} I$ orthoiodohippurate clearance in five hypoxaemic patients with chronic obstructive airways disease while they breathed air and oxygen. After oxygen for one week sodium excretion had increased and renal blood flow had increased by $20 \%$ (though this was not significant). In their discussion the authors state that renal flow fell in only one patient, who 
developed carbon dioxide retention with oxygen therapy. We avoided carbon dioxide retention by giving oxygen for short periods and found that oxygen improves renal haemodynamics (Mannix and coworkers might have had a similar result if they had excluded the patient who developed hypercapnia from their analysis). Both oxygen and carbon dioxide are likely to have important actions on the renal vasculature in cor pulmonale and it is important that future studies separate these effects.

Aminohippurate clearance techniques were used to measure renal flow in previous studies. This technique is well validated in normal subjects but may be inaccurate in patients with renal dysfunction, in which changes in the tubular handling of aminohippurate may occur. ${ }^{31}$ Changes in renal tubular function have been reported in cor pulmonale ${ }^{32}$ and the results obtained with aminohippurate techniques cannot be assumed to reflect accurately the changes in renal haemodynamics that occur with oxygen. Although Doppler ultrasound cannot measure absolute renal flow, there is good evidence, both experimentally ${ }^{22-25}$ and in patients with renal dysfunction, ${ }^{18} 19$ that the flow indices derived from the renal velocity waveform are sensitive indicators of changes in renal haemodynamics. In addition, Doppler ultrasound is non-invasive and is more likely to reflect the true state of the renal vasculature. The hypoxaemic challenges ${ }^{916}$ and invasive monitoring ${ }^{911}$ used in previous studies may have altered renal flow.

An increase in renal blood flow with oxygen could be mediated by several mechanisms, including a rise in cardiac output or carbon dioxide tension, alterations in circulating hormones acting on the kidney, or a direct action on the renal vasculature. Cardiac output is normal or even increased in most patients with hypoxaemic chronic obstructive airways disease and tends to fall with oxygen treatment. ${ }^{33}$ Increased renal blood flow due to a rise in cardiac output with oxygen therapy is therefore unlikely to explain our findings.

Increased plasma concentrations of renin, aldosterone, and atrial natriuretic peptide have been reported in patients with hypoxaemia and chronic respiratory failure. ${ }^{45163435}$ Raff et al $^{5}$ found no change in renin or angiotensin II on discontinuing oxygen therapy in patients with hypoxaemic chronic obstructive airways disease, and Winter et $a l^{35}$ found no change in atrial natriuretic peptide concentrations during oxygen therapy in patients with chronic obstructive airways disease. Reihman et $a^{16}$ reported no changes in renin, aldosterone, noradrenaline, or vasopressin concentrations with oxygen therapy in patients with chronic obstructive airways disease. More work is needed but current data do not suggest that hormones mediate the rise in renal flow with oxygen.

Changes in renal vascular resistance mediated by the carotid body could explain our findings. ${ }^{2636}$ Experimentally, hypoxic stimulation of the carotid body decreases renal blood flow and this effect is abolished in the denervated kidney. ${ }^{26}$ Although the carotid body is unlikely to be important in the normal regulation of renal flow, ${ }^{29}$ the structural changes occurring with chronic hypoxia ${ }^{36}$ could increase sympathetic outflow and renal vascular resistance. By reducing chemoreceptor stimulation oxygen therapy would increase renal flow. This hypothesis requires further study.

Our results suggest that renal haemodynamics are abnormal in hypoxaemic patients with chronic obstructive airways disease and that short term treatment with oxygen decreases renal vascular resistance. Changes in the renal circulation may be central in the pathogenesis of the fluid overload in cor pulmonale and one of the benefits of oxygen therapy may be an improvement in renal haemodynamics.

1 Anonymous. What causes oedema? [editorial]. Lancet 1988; i:1028-30.

2 Richens JM, Howard P. Oedema in cor pulmonale. Clin Sci 1982;62:255-9.

3 Harris P. Are pulmonary haemodynamics important to survival in chronic obstructive lung disease? Eur Respir $J$ 1989;2 (suppl 7):674-7S

4 Farber MO, Weinberger MH, Robertson GL, Fineberg NS, Manfredi F. Hormonal abnormalities affecting sodium and water balance in acute respiratory failure due to chronic obstructive lung disease. Chest 1984;85:49-54.

5 Raff H, Levy SA. Renin-angiotensin II-Aldosterone and ACTH-cortisol control during acute hypoxemia and exercise in patients with chronic obstructive pulmonary disease. Am Rev Respir Dis 1986;133:396-9.

6 Stuart-Harris CH, Mackinnon J, Hammond JDS, Smith WD. The renal circulation in chronic pulmonary disease and pulmonary heart failure. $Q J$ Med 1956;25:389-405.

7 Aber GM, Bishop JM. Serial changes in renal function, arterial gas tensions and the acid-base state in patients with chronic bronchitis and oedema. Clin Sci 1965;28:511-25.

8 Oliver RM, Peacock AJ, Fleming JS, Waller DG. Renal and pulmonary effects of angiotensin converting enzyme inhibition in chronic hypoxic lung disease. Thorax 1989; 44:513-5.

9 Fishman AP, Maxwell MH, Crowder CH, Morales P. Kidney function in cor pulmonale. Circulation 1951;3: 703-21.

10 Howard P. Hypoxia, almitrine, and peripheral neuropathy. Thorax 1989;44:247-50.

11 Davies CE. The effect of treatment on the renal circulation in heart-failure. Lancet 1951;ii:1052-7.

12 Platts MM, Hammond JDS, Stuart-Harris CH. A study of cor pulmonale in patients with chronic bronchitis. $Q J$ Med 1960;29:559-74.

13 Farber MO, Roberts LR, Weinberger MH, Robertson GL, Fineberg NS, Manfredi F. Abnormalities of sodium and $\mathrm{H}_{2} \mathrm{O}$ handling in chronic obstructive lung disease. Arch Intern Med 1982;142:1326-30.

14 Cannon PJ. The kidney in heart failure. N Engl J Med 1977; 296:26-32.

15 Medical Research Council Working Party. Long term domiciliary oxygen therapy in chronic hypoxic cor pulmonale complicating chronic bronchitis and emphysema. Lancet 1981; ;:681-6.

16 Reihman DH, Farber MO, Weinberger MH, Henry DP Fineberg NS, Dowdeswell IRG, et al. Effect of hypoxemia on sodium and water excretion in chronic obstructive lung disease. $A m J$ Med 1985;78:87-94.

17 Mannix ET, Dowdeswell I, Carlone S, Palange P, Aronof GR, Farber MO. The effect of oxygen on sodium excretion in hypoxemic patients with chronic obstructive lung tisease. Chest 1990;97:840-4.

18 Merritt CRB. Doppler colour flow imaging. J Clin Ultrasound 1987;15:591-7.

19 Stevens PE, Gwyther SJ, Boultbee JE, Bolsin S, Hanson ME, Kox W. Practical use of duplex Doppler analysis of the renal vasculature in critically ill patients. Lancet 1989; i:240-2.

20 Lanigan C, Ponte J, Moxham J. Performance of transcutaneous $\mathrm{PO}_{2}$ and $\mathrm{PCO}_{2}$ dual electrodes in adults. BrJ Anaesth 1988;60:736-42.

21 Yamamoto T, Tanaka H, Kimura A, Ogasawara Y, T sujioka $\mathrm{K}$, Kajiya F. Intraoperative measurement of blood velocity profiles at the human aorto-renal bifurcation. Medical and Biological Engineering and Computing 1991;29 Suppl 888.

22 Evans DH, McDicken WN, Skidmore R, Woodcock JP. Doppler ultrasound. Physics, Instrumentation and Clinical Applications. Chichester: Wiley, 1989:162-87. 
23 Taylor KJW, Burns PN, Woodcock JP, Wells PNT. Blood flow in deep abdominal and pelvic vessels: ultrasonic pulsed-doppler analysis. Radiology 1985;154:487-93.

24 Norris CS, Barnes RW. Renal artery flow velocity analysis: A sensitive measure of experimental and clinical renovascular resistance. $J$ Surg Res 1984;36:230-6.

25 Avasthi PS, Greene ER, Voyles WF, Eldridge MW. A comparison of echo-doppler and electromagnetic renal blood flow measurements. J Ultrasound Med 1984;3: 213-8.

26 Honig A. Role of the arterial chemoreceptors in the reflex control of renal function and body fluid volumes in acute arterial hypoxia. In: Acker H, O'Regan RG, eds. Physiology of the peripheral arterial chemoreceptors. Amsterdam: Elsevier, 1983:395-429.

27 Ward MP, Milledge JS, West JB, eds. High altitude medicine and physiology. London: Chapman and Hall Medical, 1989:137-60.

28 Kilburn KH, Dowell AR. Renal function in respiratory failure. Arch Intern Med 1971;127:754-62.

29 Hall JE. Regulation of renal hemodynamics. In: Guyton AC, Hall JE, eds. Cardiovascular physiology. IV. Baltimore: University Park Press, 1982:243-321. (International University Park Press, 1982.

30 Farber MO, Bright TP, Strawbridge RA, Robertson GL, Manfredi F. Impaired water handling in chronic obstruc- tive lung disease, J Lab Clin Med 1975;85:41-9.

31 Brenner BM, Zatz R, Ichikawa I. The renal circulations. In: Brenner BM, Rector FC Jr, eds. The kidney. Philadelphia: Saunders, 1986:93-123.

32 Farber MO, Weinberger MH, Robertson GL, Fineberg NS The effects of angiotensin-converting enzyme inhibition on sodium handling in patients with advanced chronic bstructive pulmonary disease. Am Rev Respir Dis 1987; obstructive 136:862-6.

33 Hunt JM, Copland J, McDonald CF, Barter CE, Rochford PD, Pierce RJ. Cardiopulmonary response to oxygen therapy in hypoxaemic chronic airflow obstruction Thorax 1989;44:930-6.

34 Ward MP, Milledge JS, West JB, eds. High altitude medicine and physiology. London: Chapman and Hall Medical, 1989:293-309.

35 Winter RJD, Davidson AC, Treacher D, Rudd RM, Anderson JV, Meleagros L, et al. Atrial natriuretic peptide concentrations in hypoxic secondary pulmonary hypertension; relation to haemodynamic and blood gas variables and response to supplemental oxygen. Thorax 1989;44: 58-62.

36 Barer G, Wach R, Pallot D, Bee D. Almatrine, hypoxia, systemic hypertension and the carotid body. In: D Heath, ed. Aspects of hypoxia. Liverpool: Liverpool University Press, 1986:113-29. 